\title{
ORIGINAL
}

\section{Serum interleukin-23 (IL-23) is increased in Hashimoto's thyroiditis}

\author{
Rosaria Maddalena Ruggeri ${ }^{1)}$, Salvatore Saitta ${ }^{2)}$, Mariateresa Cristani $^{3)}$, Salvatore Giovinazzo ${ }^{1)}$, \\ Valeria Tigano $^{2)}$, Francesco Trimarchi ${ }^{1)}$, Salvatore Benvenga ${ }^{1), 4), 5)}$ and Sebastiano Gangemi ${ }^{2),}$ ) \\ 1) Unit of Endocrinology, Department of Clinical and Experimental Medicine, University of Messina, Italy \\ 2) School and Unit of Allergy and Clinical Immunology, Department of Clinical and Experimental Medicine, University of \\ Messina, Italy \\ 3) Department Farmaco-Biologico, School of Pharmacy, University of Messina, Italy \\ 4) Master on Childhood, Adolescent and Women's Endocrine Health, University of Messina, Italy \\ 5) Interdepartmental Program of Molecular and Clinical Endocrinology \& Women's Health; A.O.U. Policlinico "G. Martino," \\ Messina, Italy \\ 6) Institute of Biomedicine and Molecular Immunology “A. Monroy” (IBIM) - Consiglio Nazionale delle Ricerche (CNR), Italy
}

\begin{abstract}
Recent studies have demonstrated that T-helper 17 lymphocytes (Th17), which produce mostly IL-17, play a major role in several autoimmune diseases commonly thought to be Th1-related, including Hashimoto's thyroiditis (HT). IL-23, a member of the IL-12 cytokine family, is known to guide T cells toward the Th17 phenotype and its serum levels are increased in several autoimmune disease. Few data are available in the literature on IL-23 in HT. Using IL-23 Quantikine ELISA Kit (lower limit of detection $2.7 \mathrm{pg} / \mathrm{mL}$ ) we analyzed the serum levels of IL-23 in 81 HT patients (75

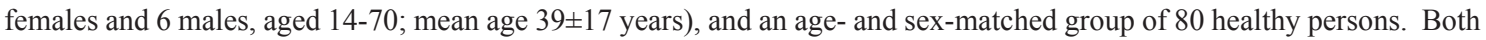
patients and controls did not receive any treatment. The positive detection rates of serum IL-23 were significantly higher in patients with HT: $56 \%$ of HT patients had detectable IL-23 in serum compared to $36 \%$ of healthy subjects (Chi $\chi^{2}$ test, $p=0.014)$. Moreover, HT patients had significantly higher serum concentrations of IL-23 $(157.38 \pm 17.92 \mathrm{pg} / \mathrm{mL})$ in comparison with healthy controls $(21.46 \pm 5.4 \mathrm{pg} / \mathrm{mL} ; p<0.0001)$. No significant correlation was found between serum levels of IL-23 and Tg-Ab or TPO-Ab levels, as well as with TSH values, in HT patients. In conclusion, serum IL-23 is increased in euthyroid and untreated HT patients, as compared to healthy subjects. Our data suggest that IL-23 would play a role in the pathogenesis of HT.
\end{abstract}

Keywords: Hashimoto's thyroiditis, Autoimmune thyroid disease, Interleukin 23, Lymphocytes T-helper 17, Cytokines

HASHIMOTO'S THYROIDITIS (HT) represents the most common organ-specific autoimmune disorder, induced by loss of immune tolerance and inappropriate immune reaction against the thyroid gland $[1,2]$. Upon antigen stimulation, activated $\mathrm{T}$ and $\mathrm{B}$ lymphocytes invade the gland and cause destruction of thyroid cells, through the activation of apoptotic pathways (both CD8+ cytotoxic lymphocyte-mediated and antibody-mediated immunity), with the help of cytokines produced by the activated T- helper lymphocytes (Th)

Submitted Nov. 13, 2013; Accepted Jan. 6, 2014 as EJ13-0484 Released online in J-STAGE as advance publication Jan. 28, 2014 Correspondence to: Rosaria Maddalena Ruggeri, M.D., Ph.D., Sezione di Endocrinologia, Dipartimento di Medicina Clinica e Sperimentale, Padiglione H, 4 piano - Policlinico Universitario "G. Martino”98125 Messina, ITALY. E-mail: rmruggeri@unime.it.
$[1,2]$. On the basis of the cytokine secretion profile, CD4+ Th lymphocytes were originally subdivided into Th1 and Th2 cells. Th1 produce interleukin 2 (IL-2), interferon $\gamma($ IFN- $\gamma)$, and lymphotoxin and induce cellular responses $[3,4]$. Th2 cells secrete IL-4, IL-5, IL-6, IL-9, IL-10, and IL-13 and promote production of antibodies by B lymphocytes [3,4]. A predominant Th1-driven autoimmune response has been clearly recognized in HT, while Graves' disease (GD) is induced by thyroid stimulating autoantibodies to TSH receptor and is considered a Th2-related disease [3, 4]. Another subset of CD4+ lymphocytes (Th3) synthesizes mainly TGF- $\beta$ and is involved in regulation of the adaptive immune response, the so-called regulatory T-cells or Treg [5]. Recent studies revealed that a novel T-cell subset, the Th17 cells producing mostly 
IL-17, IL-21 and IL-22, is involved in numerous autoimmune diseases (AID) commonly thought to be Th1 diseases, including HT [6-9]. Moreover, the proportion of peripheral Th17 cells has been found to be higher in patients affected by severe GD than in GD patients in remission [9]. Cytokines produced by the activated $\mathrm{T}$ lymphocytes may contribute to drive the autoimmune response skewing toward the Th17 phenotype and away from Th1 or Th2 phenotypes. Beside the wellknown role of IL-6, a pivotal role in the immune balance has been ascribed more recently to interleukin 23 (IL-23).

IL-23 is a heterodimeric cytokine, belonging to the IL-12 family, composed of a unique 19 subunit, and a common p40 subunit shared with IL-12 [10, 11]. Both cytokines are produced by dendritic cells and macrophages, namely the antigen presenting cells (APC). The two cytokines, however, have divergent activities. IL-12 promotes the development of interferon-producing Th1 cells, while IL-23 is one of the essential factors required for the expansion of Th17 cells population $[10,11]$. Recent studies have indicated that IL-23 regulates autoimmune-inflammatory processes in several mouse disease models [12-15] and may also represent a therapeutic target by using a specific antibody against the $\mathrm{p} 40$ subunit $[16,17]$. Moreover, the IL-23 receptor (IL-23R) gene has been identified as a major susceptibility gene for several autoimmune diseases, including Graves' disease [18].

Very recent data are emerging on the role of IL-23 in autoimmune thyroid diseases (AITD), but most of them are focused on Graves' disease [19-21]. Aim of the present study was to evaluate the concentrations of serum IL-23 in a series of euthyroid and untreated patients affected by HT.

\section{Materials and Methods}

\section{Patients and study design}

A total of 81 consecutive patients ( 75 females and 6 males, aged 14-70; mean age $39 \pm 17$ years) affected by Hashimoto's thyroiditis (HT) where recruited from the outpatient clinic of our Endocrine Unit from January to June 2013. HT was diagnosed by the currently accepted clinical, laboratory and US criteria [22-24]. All patients were not taking L-T4 therapy or drugs affecting thyroid function at the time of sampling. Eighty age- and sex-matched healthy subjects (74 females and 6 males, mean age, $40 \pm 15$ years) were also recruited as controls, after taking a history to rule out current and past thyroid illness as well as any autoimmune-related disease. None of the patients or control subjects had history of neoplastic disease and symptoms or laboratory signs of inflammatory diseases (including non-thyroid AID), asthma and other allergic disorders, active infections, diabetes mellitus or kidney failure.

Serum free thyroxine (FT4), free triiodothyronine (FT3) and thyrotropin (TSH) concentrations were measured in each patient and healthy control to asses thyroid function. In all patients and controls we also measured serum thyroglobulin antibody ( $\mathrm{Tg}-\mathrm{Ab})$ and thyroid peroxidase antibody (TPO-Ab) levels and performed thyroid ultrasonography (US). All goitrous patients underwent US-guided fine needle aspiration biopsy (FNAB) of one or more selected nodules, and only patients with cytological features of colloid goiter were included in the study.

The study was approved by the local Ethics Committee. Informed consent was obtained by the patients and control subjects.

\section{Methods}

Peripheral blood samples were collected after overnight fasting from all the recruited patients and controls, and the serum was stored at $-20^{\circ} \mathrm{C}$ for cytokine assay. Serum levels of IL-23 were measured by a quantitative enzyme immunoassay technique, by using the IL-23 Quantikine ELISA Kit according to the manufacturer's instructions (R \& D System, Minneapolis, USA). A microplate reader (BioRad Laboratories, Model 550, Milan, Italy) capable of measuring absorbance at $450 \mathrm{~nm}$ was used to measure the intensity of color developed in each well. All assays were done in duplicate. The detection limit of the assay was $2.7 \mathrm{pg} /$ $\mathrm{mL}$. Intra-assay and inter-assay $\mathrm{CV}$ s were less than $4.5 \%$ and $8.4 \%$, respectively.

Serum FT4, FT3 and TSH concentrations were measured by immunoenzymatic method (commercial kits by Medical Systems, Genoa, Italy; normal values in our laboratory: $10.3-24.6 \mathrm{pmol} / \mathrm{L}$ and $2.7-6.45 \mathrm{pmol} / \mathrm{L}$ for FT4 and FT3, respectively; $0.4-4.0 \mathrm{mU} / \mathrm{L}$ for TSH). $\mathrm{Tg}-\mathrm{Ab}$ and $\mathrm{TPO}-\mathrm{Ab}$ were measured by the corresponding immunoradiometric assay kit by DiaSorin (Saluggia, Italy); normal values are $<100 \mathrm{U} / \mathrm{mL}$ and $<10 \mathrm{U} / \mathrm{mL}$, respectively. The intra- or the inter-assay coefficients of variation, for all assays, were less than $5 \%$ and less than $10 \%$, respectively.

A real-time 2D apparatus (General Electric 
Healthcare, USA) with a 7,5-10 MHz linear transducer was used to perform thyroid US.

\section{Statistical Analysis}

Data are expressed as mean and median \pm SEM. Differences between data series (IL-23 serum levels) were analyzed by Mann-Whitney test. Differences between categorical groups (detection rate) were analyzed by Pearson chi square $\left(\chi^{2}\right)$ test. Correlation between two variables was evaluated with Spearman's rho. The statistical analysis was performed by SPSS for windows version 17.0. The level of statistical significance was always set at $p<0.05$.

\section{Results}

The characteristics of our study population are summarized in Table 1. There was no statistical difference in age or sex distribution between the groups. Concerning thyroid functional status, all HT patients had normal values of FT4 and FT3, with TSH concentrations ranging from 0.6 and $6.0 \mathrm{mU} / \mathrm{L}$ and a mean value of $2.4 \pm$ $1.5 \mathrm{mU} / \mathrm{L}$. All control subjects were euthyroid, with TSH mean values of $1.8 \pm 0.7 \mathrm{mU} / \mathrm{L}$. Thus, TSH values were significantly higher in HT patients as compared to healthy controls $(p<0.01)$. However, only 9 out of 81 HT patients had mildly increased serum TSH levels $(\leq 6 \mathrm{mU} / \mathrm{L})$, with free thyroid hormone levels within their respective reference ranges.

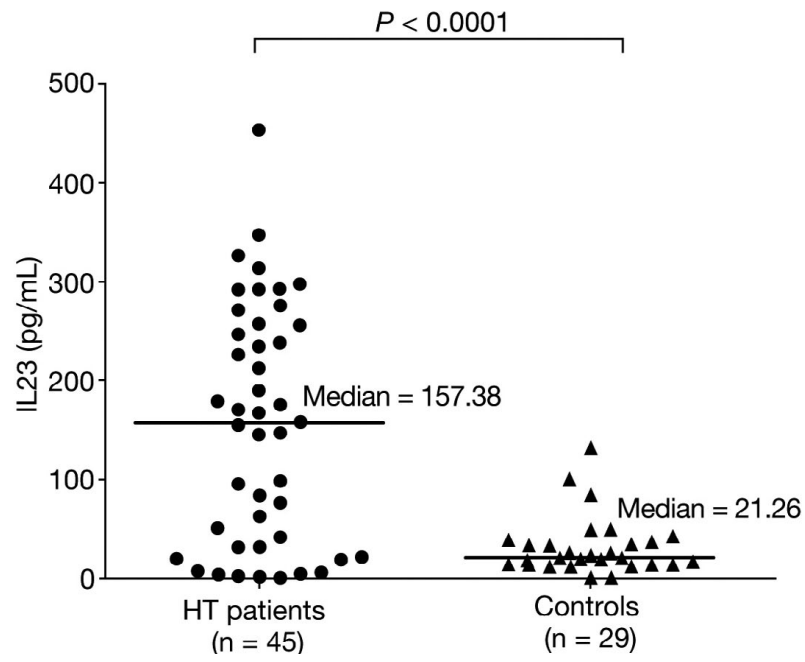

Fig. 1 Dotplot representing serum levels of IL-23 in HT patients and in control subjects. Lines represented medians.

We analyzed the serum levels of IL-23 in all 161 participants (81 HT patients and 80 healthy controls). Among the normal controls, only 29 subjects out of 80 $(36 \%)$ had detectable IL-23 in serum. Among the 81 HT patients, 45 (56\%) had detectable serum levels of IL-23. There was a statistical difference in the detection rate between HT patients and healthy subjects ( $p=$ 0.014).

Median values of serum IL-23 in the two groups of patients are shown in Fig. 1. There was a significant difference between the two groups $(p<0.0001)$. We

Table 1 Clinical, biochemical and sonographic characteristics of patients and controls participants

\begin{tabular}{|c|c|c|c|}
\hline & HT patients $(n=81)$ & Healthy controls $(\mathrm{n}=80)$ & \\
\hline \multicolumn{4}{|l|}{ Sex } \\
\hline male & 6 & 6 & \\
\hline female & 75 & 74 & \\
\hline \multicolumn{4}{|l|}{ Age } \\
\hline mean $\pm \mathrm{SD}$ (range) & $39 \pm 17(14-70)$ & $40 \pm 15(15-70)$ & $\mathrm{NS}^{\mathrm{a}}$ \\
\hline $\mathrm{TSH}(\mathrm{mIU} / \mathrm{L})^{*}$ & $2.4 \pm 1.5$ & $1.8 \pm 0.7$ & $P<0.01^{\text {a }}$ \\
\hline FT3 $(\mathrm{pmol} / \mathrm{L})^{*}$ & $4.4 \pm 0.9$ & $4.2 \pm 0.9$ & $\mathrm{NS}^{\mathrm{a}}$ \\
\hline $\mathrm{FT} 4(\mathrm{pmol} / \mathrm{L})^{*}$ & $14.9 \pm 2.6$ & $15.7 \pm 2.5$ & $\mathrm{NS}^{\mathrm{a}}$ \\
\hline $\operatorname{Tg}-\mathrm{Ab}(\mathrm{U} / \mathrm{L})^{*} \S$ & $375(145-4000)$ & Absent & \\
\hline $\mathrm{TPO}-\mathrm{Ab}(\mathrm{U} / \mathrm{L})^{* \S}$ & $194(50-4770)$ & Absent & \\
\hline Thyroid volume $(\mathrm{mL})^{*}$ & $15 \pm 4.3$ & $12 \pm 3.4$ & $\mathrm{NS}^{\mathrm{a}}$ \\
\hline
\end{tabular}


found that serum IL-23 levels were significantly higher in HT patients $(157.38 \pm 17.92 \mathrm{pg} / \mathrm{mL})$ in comparison with healthy controls $(21.46 \pm 5.4 \mathrm{pg} / \mathrm{mL} ; p<0.0001)$.

No significant correlation was found between IL-23 levels and serum levels of Ab-Tg and Ab-TPO in HT patients (rho $=-0.277$ and $=-0.281 ; p=0.225$ and 0.133 , respectively).

Similarly, no significant correlation was found between IL-23 levels and serum levels of TSH, FT3 and FT4 in HT patients (rho $=-0.236,0.288$ and 0.048; $p=0.137,0.288$ and 0.786 , respectively).

\section{Discussion}

IL-23 has an important role in the pathogenesis of several inflammatory and autoimmune conditions, mostly through the expansion of the Th17 cells [12-17]. Despite evidence from the literature demonstrating that Th17 lymphocytes play a major role in AITD, very few studies have focused their attention on IL-23 levels in these patients, and most of them concerned GD $[18,20]$. Only one paper is available in the literature in which serum levels of IL-23 were measured in HT patients [21]. In this study, FigueroaVega and co-workers studied a small series of AITD patients, including $13 \mathrm{HT}$ and $5 \mathrm{GD}$. They found enhanced levels of $\mathrm{T}$ cells synthesizing IL-17 and IL-22 in the peripheral blood from the AITD patients, mainly in those with HT. Furthermore, they measured the serum levels of the related cytokines IL-6, IL-15 and IL-23, that are known to promote Th17 differentiation, and found that IL-6 and IL-15 levels were significantly increased, while serum levels of IL-23 tended to be higher in sera from HT patients. Accordingly, an enhanced in vitro differentiation of $\mathrm{T}$ lymphocytes into Th17 cells induced by IL-6/IL-23 was observed [21]. No other data are available in the literature on IL-23 in HT patients.

In the present study, we measured the serum levels of IL-23 in a large series HT patients and compared these values with those measured in healthy subjects without thyroid disease. Because both patients and control subjects were enrolled at the time of diagnosis and had not received any form of medical treatment, no confounding variables for serum IL-23 can be discerned.

We found that both the detection rates and the serum concentrations of IL-23 were significantly higher in HT compared to healthy controls. The increase of IL-23 serum levels, that Figueroa-Vega and co-workers had reported in their study on 13 HT patients, reachs statistical relevance in our study, due to the high number of subjects studied. These data suggest that IL-23 is involved in the development of HT and further support the role of Th17 cells in AITD, in line with the data from the literature [7-9, 21]. An enhanced production of IL-23 by APCs may drive the immune response towards a Th17 phenotype and contribute to promote the autoimmune inflammation of the gland. Noteworthy, our study group consisted of untreated HT patients, and most of them were euthyroid, only few patients displaying a slight elevation of TSH and thus they did not receive any treatment. Thus, our findings could reflect an early step in the natural course of HT.

In the present study, no significant correlation was found between IL-23 and Ab-Tg or Ab-TPO level in HT patients. However, also in the above cited study by Figueroa-Vega, no correlation with Ab levels was mentioned [21]. This lack of correlation may be due to the fact that only patients developing thyroid autoimmunity with preserved thyroid function were taken into account in this study. It is reasonable to hypothesize that such a correlation may be more evident in patients in more advanced stages of disease (eg. hypothyroid patients), who shown a microenvironment more enriched in autoreactive immune cells activated by APCs infiltrating the gland.

We could not correlate IL-23 serum levels with thyroid functional status because all the studied subjects were euthyroid or displayed only a slight elevation of TSH $(\leq 6 \mathrm{mU} / \mathrm{L})$. However, no significant correlation was found between IL-23 and TSH levels in HT patients.

In conclusion, we found higher detection rate and higher serum concentrations of IL-23 in HT patients. Serum IL-23 elevation may play a role in the pathogenesis of HT, guiding T cells towards the Th17 phenotype and promoting the autoimmune inflammation of the gland. Further longitudinal studies will be required to confirm these data, in order to better clarify the serum changes in cytokines levels from the onset of the thyroid autoimmune process throughout its clinical course, and to better define the natural history of AITD.

\section{Disclosure Section}

None of the authors have any potential conflict of interest associated with this research. 


\section{References}

1. Weetman AP (2004) Cellular immune responses in autoimmune thyroid disease. Clin Endocrinol (Oxf) 61: 405413.

2. Fountoulakis S, Tsatsoulis A (2004) On the pathogenesis of autoimmune thyroid disease: a unifying hypothesis. Clin Endoclinol (Oxf) 60: 397-409.

3. Fisfalen ME, Palmer EM, Van Seventer GA, Soltani K, Sawai Y, et al. (1997) Thyrotropin-receptor and thyroid peroxidase-specific $\mathrm{T}$ cell clones and their cytokine profile in autoimmune thyroid disease. J Clin Endocrinol Metab 82: 3655-3663.

4. Phenekos C, Vryonidou A, Gritzapis AD, Baxevanis CN, Goula M, et al. (2004) Th1 and Th2 serum cytokine profiles characterize patients with Hashimoto's thyroiditis (Th1) and Graves' disease (Th2). Neuroimmunomodulation 11: 209-213.

5. Fountoulakis S, Vartholomatos G, Kolaitis N, Frillingos S, Philippou G, et al. (2008) HLA-DR expressing peripheral $\mathrm{T}$ regulatory cells in newly diagnosed patients with different forms of autoimmune thyroid disease. Thyroid 18: 1195-1200.

6. Ouyang W, Kolls JK, Zheng Y (2008) The biological functions of $\mathrm{T}$ helper 17 cell effector cytokines in inflammation. Immunity 28: 454-467.

7. Horie I, Abiru N, Nagayama Y, Kuriya G, Saitoh O, et al. (2009) $\mathrm{T}$ helper type 17 immune response plays an indispensable role for development of iodine-induced autoimmune thyroiditis in non-obese diabetic- $\mathrm{H} 2 \mathrm{~h} 4$ mice. Endocrinology 150: 5135-5142.

8. Shi Y, Wang H, Su Z, Chen J, Xue Y, et al. (2010) Differentiation imbalance of Th1/Th17 in peripheral blood mononuclear cells might contribute to pathogenesis of Hashimoto's thyroiditis. Scand J Immunol 72: 250-255.

9. Nanba T, Watanabe M, Inoue N, Iwatani Y (2009) Increases of the Th1/Th2 cell ratio in severe Hashimoto's disease and in the proportion of Th17 cells in intractable Graves' disease. Thyroid 19: 495-501.

10. Oppmann B, Lesley R, Blom B, Timans JC, Xu Y, et al. (2000) Novel p19 protein engages IL-12p40 to form a cytokine, IL-23, with biological activities similar as well as distinct from IL-12. Immunity 13: 715-725.

11. Parham C, Chirica M, Timans J, Vaisberg E, Travis M, et al. (2002) A receptor for the heterodimeric cytokine IL-23 is composed of IL-12Rbeta1 and a novel cytokine receptor subunit, IL-23R. J Immunol 168: 5699-5708.

12. Cua DJ, Sherlock J, Chen Y, Murphy CA, Joyce B, et al. (2003) Interleukin-23 rather than interleukin-12 is the critical cytokine for autoimmune inflammation of the brain. Nature 421: 744-748.

13. Murphy CA, Langrish CL, Chen Y, Blumenschein W,
McClanahan T, et al. (2003) Divergent pro- and antiinflammatory roles for IL-23 and IL-12 in joint autoimmune inflammation. J Exp Med 198: 1951-1957.

14. Langrish CL, Chen Y, Blumenschein WM, Mattson J, Basham B, et al. (2005) IL-23 drives a pathogenic T cell population that induces autoimmune inflammation. J Exp Med 201: 233-240.

15. Yen D, Cheung J, Scheerens H, Poulet F, McClanahan T, et al. (2006) IL-23 is essential for T cell-mediated colitis and promotes inflammation via IL-17 and IL-6. $J$ Clin Invest 116: 1310-1316.

16. Brok HP, van Meurs M, Blezer E, Schantz A, Peritt D, et al. (2002) Prevention of experimental autoimmune encephalomyelitis in common marmosets using an antiIL-12p40 monoclonal antibody. J Immunol 169: 65546563.

17. Chen Y, Langrish CL, McKenzie B, Joyce-Shaikh B, Stumhofer JS, et al. (2006) Anti-IL-23 therapy inhibits multiple inflammatory pathways and ameliorates autoimmune encephalomyelitis. J Clin Invest 116: 13171326.

18. Huber AK, Jacobson EM, Jazdzewski K, Concepcion ES, Tomer Y (2008) Interleukin (IL)-23 receptor is a major susceptibility gene for Graves' ophthalmopathy: the IL-23/T-helper 17 axis extends to thyroid autoimmunity. J Clin Endocrinol Metab 93: 1077-1081.

19. Zheng L, Ye P, Liu C (2013) The role of the IL-23/IL-17 axis in the pathogenesis of Graves' disease. Endocr $J$ 60: 591-597.

20. Kim SE, Yoon JS, Kim KH, Lee SY (2012) Increased serum interleukin-17 in Graves' ophthalmopathy. Graefes Arch Clin Exp Ophthalmol 250: 1521-1526.

21. Figueroa-Vega N, Alfonso-Pérez M, Benedicto I, Sánchez-Madrid F, González-Amaro R, et al. (2010) Increased circulating pro-inflammatory cytokines and Th17 lymphocytes in Hashimoto's thyroiditis. J Clin Endocrinol Metab 95: 953-962.

22. Brent GA, Davies TF (2012) Hypothyroidism and thyroiditis. In: Melmed S, Polonsky KS, Larsen PR, Kronenberg HM (eds) $12^{\text {th }}$ Edition Williams Textbook of Endocrinology, Saunders, Philadelphia; pp, 423456.

23. Vejbjerg P, Knudsen N, Perrild H, Laurberg P, Pedersen IB, et al. (2006) The association between hypoechogenicity or irregular echo pattern at thyroid ultrasonography and thyroid function in the general population. Eur $J$ Endocrinol 155: 547-552.

24. Benvenga S, Trimarchi F (2008) Changed presentation of Hashimoto's thyroiditis in North-Eastern Sicily and Calabria (Southern Italy) based on a 31-year experience. Thyroid 18: 429-441. 